\title{
Exposure to grain dust and changes in lung function
}

\author{
A L James, M J Zimmerman, H Ee, G Ryan, A W Musk
}

\begin{abstract}
Respiratory symptoms and lung function were assessed in 41 seasonal grain handlers and related to duration of employment and level of exposure to grain dust. Ten public works department employees, not exposed to grain dust, were examined during the same period. Respiratory symptoms, forced expired volume in one second $\left(F E V_{1}\right)$, and bronchial responsiveness (dose of methacholine provoking a $20 \%$ fall in $\mathbf{F E V} \mathbf{F}_{1}-\mathbf{P D}_{20}$ ) were assessed before starting work and at weekly intervals during a period of employment lasting up to four weeks. Two atopic grainhandlers with pronounced bronchial hyperresponsiveness $\left(\mathbf{P D}_{20}<1\right.$ $\mu \mathrm{mol})$ and a history of asthma withdrew from the study within two weeks because they developed severe asthma. Respiratory symptoms were more frequent and more often attributed to work in the grainhandlers than in the non-exposed subjects. In the grainhandlers the FEV 1 decreased by a mean $(95 \%$ confidence intervals) of $321 \mathrm{ml}(198-444)(\mathrm{p}<0.05)$ and the mean (95\% confidence interval) $\mathbf{P D}_{20}$ decreased from $20.6 \mu \mathrm{mol}(10.3-41.2)$ to 6.0 $\mu$ mol $(2.8-12.5)(p<0.05)$ after one week of work. Over the next three weeks the mean FEV returned towards the prestudy values. The mean $\mathbf{P D}_{20}$, however, remained significantly lower than the initial value. The mean FEV and $\mathbf{P D}_{20}$ did not change significantly in the non-exposed subjects. The frequency of symptoms and decreases in $\mathrm{FEV}_{1}$ were greater in grainhandlers when working in jobs where total exposure to dust was $>20 \mathrm{mg} / \mathrm{m}^{3}$ than when working in jobs where it was $<10 \mathrm{mg} / \mathrm{m}^{3}$. The results indicate that occupational exposure to grain dust results in respiratory symptoms and changes in lung function, including increased airway responsiveness, within the first week of exposure to grain dust
\end{abstract}

Department of Respiratory Medicine, Sir Charles Gairdner Hospital, The Queen Elizabeth II Medical Centre, Nedlands, Western Australia 6009

A L James

M J Zimmerman

$\mathrm{H} \mathrm{Ee}$

G Ryan

A W Musk at work. These changes appear to be determined by the degree of dust exposure and suggest a direct effect of grain dust on the lung in these subjects.

Occupational exposure to grain dust is associated with the development of respiratory symptoms and acute and long term changes in lung function. ${ }^{1}$ Most workers in studies performed elsewhere have had many years of exposure to grain dust and probably represent healthy survivor populations, suggested by a lower prevalence of symptoms and atopy in these populations compared with the general population. ${ }^{2}$

Western Australian seasonal grainhandlers with little or no previous occupational exposure to grain dust have reported cough, wheeze, and dyspnoea after short periods of exposure to grain dust. ${ }^{3}$ The symptoms were associated with a pre-employment history of wheeze, positive prick skin test reponses to fungal antigens, and to the presence of increased airway responsiveness to methacholine. ${ }^{3}$ In a subsequent study symptoms were found to be associated with small reductions in $\mathrm{FEV}_{1}$ over a six to eight week harvest season. ${ }^{4}$ These studies have suggested that allergic factors and airway responsiveness may be important determinants of the acute respiratory response to grain dust. The time course of symptoms and changes in lung function, however, and their relation to level of dust exposure have not previously been studied in these workers.

The aims of the present study were to determine the relation between respiratory symptoms and changes in lung function and duration and degree of exposure to grain dust in seasonal grainhandlers.

\section{Subjects}

During the annual grain harvest in Western Australia extra staff are employed to perform a variety of jobs. Forty one seasonal grainhandlers starting employment at a single grain handling terminal were entered into the study at weekly intervals over a three week period when they attended for a preemployment briefing about their work. These subjects represented $71 \%$ of the extra personnel temporarily employed for the season. Eighty five per cent of the subjects lived in the surrounding wheat growing district, although they had not worked with 
grain for at least nine months and $51 \%$ had never worked with grain.

Job allocations included shunting, tipping and emptying loaded train carriages, sweeping around conveyor belts, sampling the grain, operating tipping ramps, unloading lorries in flat storage facilities, and reloading trains for transport. Shifts (day or night) were eight to 12 hours long, with two breaks, for seven days a week. Employees changed shift and job (and hence level of exposure to grain dust) according to a roster every week. Work was continuous during the period of employment, although its total duration for each grainhandler varied considerably as they were hired and then retrenched according to the amount of grain being handled.

Ten machinery maintenance employees of a nearby public works department volunteered and were studied during the same period to compare frequency of symptoms and levels of lung function in subjects who were not occupationally exposed to grain dust. These men lived in the same township as the grainhandlers and worked about five kilometres from the grain storage site. Three had worked with grain in the past (farming, grain terminal, animal feed factory) but none within the past five years. Informed consent was obtained from all subjects.

\section{Methods}

On entry all subjects completed a standard questionnaire on respiratory symptoms and forced expiratory volume in one second $\left(\mathrm{FEV}_{1}\right)$, forced vital capacity (FVC), peak expiratory flow (PEF), and bronchial responsiveness to inhaled methacholine were measured. Prick skin test responses to a variety of common antigens were performed and a blood sample was taken to measure serum IgE uptake to grain dust. At work PEF was measured before, during, and after each shift. At weekly intervals a second questionnaire was administered and $F E V_{1}$, FVC, and bronchial responsiveness were remeasured. At the end of employment all these measurements were repeated in addition to prick skin tests and IgE uptake. The non-exposed subjects were studied by the same observers using the same equipment over the same study period as the grainhandlers. In addition for the grainhandlers the total inspirable grain dust level for each job category was measured twice during the study.

Subjects answered the British Medical Research Council questionnaire on respiratory symptoms, smoking history, and occupational history with additional questions concerning previous exposure to grain dust. ${ }^{5}$ At the end of each week during the study all subjects completed a second questionnaire recording the occurrence of runny nose, eye irritation, cough, sputum, wheeze, shortness of breath, and chest tightness during the previous week. Collection of the questionnaire responses at the end of the first week of work was incomplete and could not be usefully used in the analysis.

FEV $_{1}$ and FVC were measured using a dry bellows spirometer (Vitalograph, Buckingham, UK). The best measurement obtained from three technically satisfactory forced expiratory manoeuvres that differed by less than $5 \%$ was recorded. For comparison between grainhandlers and the non-exposed subjects FEV $_{1}$ and FVC were expressed as the percentage of the predicted normal value. ${ }^{6}$ PEF was measured under the supervision of a technician using MiniWright peak flow meters (Clement Clarke International, London). The best of three PEF measurements was recorded before work, at the midshift break, and at the end of each shift. The daily variability of peak flow was calculated as: (maximum PEF - minimum PEF)/maximum PEF. This was averaged over each week to obtain the mean daily peak flow variability.

Airway responsiveness to inhaled methacholine was measured using a modification of the method of Yan et al. ${ }^{7}$ Aerosols of saline or methacholine were delivered from eight calibrated De Vilbis nebulisers driven by compressed air. The nebulisers contained increasing concentrations of methacholine $(2 \cdot 5,5,25$, $50,100,250$, and $500 \mathrm{mg} / \mathrm{ml}$ ) and by varying the number of puffs, a series of 13 approximately doubling doses was given. Inhalations were continued until the $\mathrm{FEV}_{1}$ fell by $20 \%$ of the postsaline value or until the maximum cumulative dose of $250 \mu \mathrm{g}$ had been given. The dose of methacholine provoking a $20 \%$ fall in $\mathrm{FEV}_{1}\left(\mathrm{PD}_{20}\right)$ was calculated by interpolation of the log dose response curve or by extrapolation up to one doubling dose if the dose response curve was linear.

Four groups of antigens were used for skin testing: "grain extracts" (whole grain wheat, rye, oats, barley, wheat smut), "fungal extracts" (aspergillus, penicillium, cladosporium, alternaria), "grass pollen extracts" (canary grass, Bermuda grass, wild oats, perennial rye grass), and "housedust mite extracts" (Dermatophagoides farinae, D pteronyssinus) (all Hollister Stier, Spokane, Wash, except $D$ pteronyssinus, Dome, Sydney). Reactions were measured at 15 minutes after skin prick and weals $\geqslant 3 \mathrm{~mm}$ in diameter relative to the saline control were considered as positive. Subjects were classified as atopic if there was one or more positive test.

A $10 \mathrm{ml}$ sample of venous blood was taken from each subject and the separated serum was frozen and stored at $-70^{\circ} \mathrm{C}$ before being sent to the Commonwealth Scientific and Industrial Research Organisation (CSIRO) Wheat Research Unit (Sydney). Sera were tested for IgE uptake to crude grain dust allergens, separated using aqueous and non-aqueous $(\mathrm{KOH})$ solvents. Subjects with more than $2 \% \mathrm{IgE}$ uptake were categorised as responders.

In the grainhandlers samples of airborne dust were 
collected on two different occasions at each job using personal dust samplers with an airflow rate of $21 / \mathrm{min}$ (Du Pont P2500-Wilmington, MSA Model GPittsburgh or Rotheroe and Mitchell L2SF-Ruislip) and PVC filter papers with pore size 5 micron. Total inspirable dust concentration was measured and jobs where dust concentrations were found to be less than $10 \mathrm{mg} / \mathrm{m}^{3}$ were designated as "low dust." Jobs where dust concentrations were found to be greater than 20 $\mathrm{mg} / \mathrm{m}^{3}$ were designated as "high dust." No jobs had a total inspirable dust concentration in the range 10-20 $\mathrm{mg} / \mathrm{m}^{3}$.

Differences between groups were tested using the Students $t$ test for continuous variables and the Chi squared test for categorical variables. Log transformation of $\mathrm{PD}_{20}$ was used for statistical analysis. Changes in lung function with time were analysed by comparing group means at intervals after starting work to the mean prestudy value. Since some subjects remained at work for longer than others the lung function results of those grainhandlers who completed all tests were compared with the results of the whole group to detect any effect of healthier subjects working, and being studied, for longer.

\section{Results}

Seven $(17 \%)$ grainhandlers stopped work prematurely. Two developed troublesome cough and wheeze within one week of starting employment and recorded a decrease in $\mathrm{FEV}_{1}(420 \mathrm{ml}$ and $960 \mathrm{ml})$ from prestudy measurements. They were both atopic on skin testing and their prestudy $\mathrm{PD}_{20}$ was low; 0.433 and $0.074 \mu \mathrm{mol}$. They had answered "no" to a history of asthma and one subject had answered "yes" to a history of wheeze on the prestudy questionnaire. On further questioning after they had left work both gave histories suggesting asthma (episodic

Table 1 Prestudy characteristics of subjects

\begin{tabular}{|c|c|c|}
\hline & $\begin{array}{l}\text { Grain } \\
\text { handlers } \\
(n=41)\end{array}$ & $\begin{array}{l}\text { Non-exposed } \\
\text { subjects } \\
(n=10)\end{array}$ \\
\hline $\begin{array}{l}\text { Age }(y)(\text { mean } \pm \text { SD) } \\
\text { Smokers }(\%) \\
\text { Ex-smokers }(\%) \\
\text { Prior grain dust exposure }(\%)\end{array}$ & $\begin{array}{l}27 \pm 11 \\
62 \\
17 \\
49\end{array}$ & $\begin{array}{l}50 \pm 12^{\star} \\
20^{\star} \\
60 \\
30\end{array}$ \\
\hline $\begin{array}{l}\text { History of respiratory disease: } \\
\text { Hay fever (\%) } \\
\text { Asthma (\%) } \\
\text { Bronchitis }(\%)\end{array}$ & $\begin{array}{r}22 \\
5 \\
25\end{array}$ & $\begin{array}{r}50 \\
0 \\
30\end{array}$ \\
\hline $\begin{array}{l}\text { Lung function (mean } \pm \text { SD): } \\
\text { FEV }, \% \text { predicted } \\
\text { FVC, \% predicted } \\
\text { PD }_{20}, \mu \text { mol } \\
\text { Prick skin test ( } \% \text { positive): }\end{array}$ & $\begin{array}{l}95 \pm 12 \\
99 \pm 12 \\
20 \cdot 6 \pm 8 \cdot 4\end{array}$ & $\begin{array}{l}100 \pm 13 \\
99 \pm 17 \\
28 \cdot 4 \pm 4 \cdot 8\end{array}$ \\
\hline $\begin{array}{l}\text { Grain } \\
\text { Mite } \\
\text { Grass } \\
\text { Fungi } \\
\text { Any } \\
\text { RAST responders }(\%)\end{array}$ & $\begin{array}{l}17 \\
29 \\
44 \\
10 \\
59 \\
17\end{array}$ & $\begin{array}{l}20 \\
20 \\
40 \\
40^{\star} \\
40 \\
13\end{array}$ \\
\hline
\end{tabular}

${ }^{\star} \mathrm{p}<0.05$ compared with grainhandlers.
Table 2 Percentage of grainhandlers and non-exposed subjects with symptoms

\begin{tabular}{|c|c|c|c|c|}
\hline & & \multirow[b]{2}{*}{$\begin{array}{l}\text { Before } \\
\text { work }\end{array}$} & \multicolumn{2}{|c|}{$\begin{array}{l}\text { Occurrence of symptoms } \\
\text { at work }\end{array}$} \\
\hline & & & $\begin{array}{l}\text { After } \\
\text { two weeks }\end{array}$ & $\begin{array}{l}\text { At any } \\
\text { time }\end{array}$ \\
\hline $\begin{array}{l}\text { Cough } \\
\text { Phlegm } \\
\text { Wheeze } \\
\text { Chest tightness } \\
\text { Shortness of breath }\end{array}$ & $\begin{array}{l}\mathbf{G} \\
\mathbf{N} \\
\mathbf{G} \\
\mathbf{N} \\
\mathbf{G} \\
\mathbf{N} \\
\mathbf{G} \\
\mathbf{N} \\
\mathbf{G} \\
\mathbf{N}\end{array}$ & $\begin{array}{r}32 \\
50 \\
42 \\
50 \\
22 \\
30 \\
12 \\
50 \\
7 \\
40\end{array}$ & $\begin{array}{l}56^{\star} \\
20 \\
54 \\
20 \\
31 \\
10 \\
28 \\
0 \\
23 \\
0\end{array}$ & $\begin{array}{l}83 \\
70 \\
71^{\star} \\
30 \\
46^{\star} \\
10 \\
54 \\
70 \\
27 \\
40\end{array}$ \\
\hline
\end{tabular}

$\mathbf{G}=$ Grainhandlers; $\mathbf{N}=$ non-exposed subjects.

${ }^{\star} p<0.05$ Grainhandlers compared with non-exposed subjects.

dyspnoea, wheeze, and chest tightness). Three grainhandlers left work due to other commitments, one declined further assessment, and one had stopped work after a train accident.

At the initial assessment grainhandlers currently smoked more, were younger, and reported fewer previous respiratory symptoms than the nonexposed subjects (table 1). The frequency of previous exposure to grain, history of respiratory disease, or lung function results did not differ between grainhandlers and non-exposed subjects. Positive prick skin test responses to fungal extracts were more common in the non-exposed subjects. Symptom frequency, atopy, or lung function did not differ between grainhandlers who had worked with grain previously and those who had not.

The results of dust sampling in the grainhandlers showed two distinct groups: high dust (range 21-28 $\mathrm{mg} / \mathrm{m}^{3}$ ) and low dust (range $0-8 \cdot 2 \mathrm{mg} / \mathrm{m}^{3}$ ). High dust concentrations were measured in jobs involving grain storage and the unloading and reloading of trains. Low dust concentrations were measured during sampling of grain in incoming trucks, office duties, sweeping, shunting of trains, work attending the conveyor belts, and tipping grain from rail trucks. The distribution of jobs into categories of high and low dust concentration was identical for the two periods of sampling.

Respiratory symptoms were reported more frequently at the initial assessment by the nonexposed subjects than by the grainhandlers, but after two weeks (symptom reporting was incomplete at the end of the first week of work) at work this pattern was reversed (table 2). Grainhandlers also reported more symptoms except for shortness of breath and chest tightness at any time during the period of work. In addition, grainhandlers more often attributed cough, phlegm, and chest tightness to work than the nonexposed subjects $(p<0.05)$.

In the first week 34 of the grainhandlers recorded a 


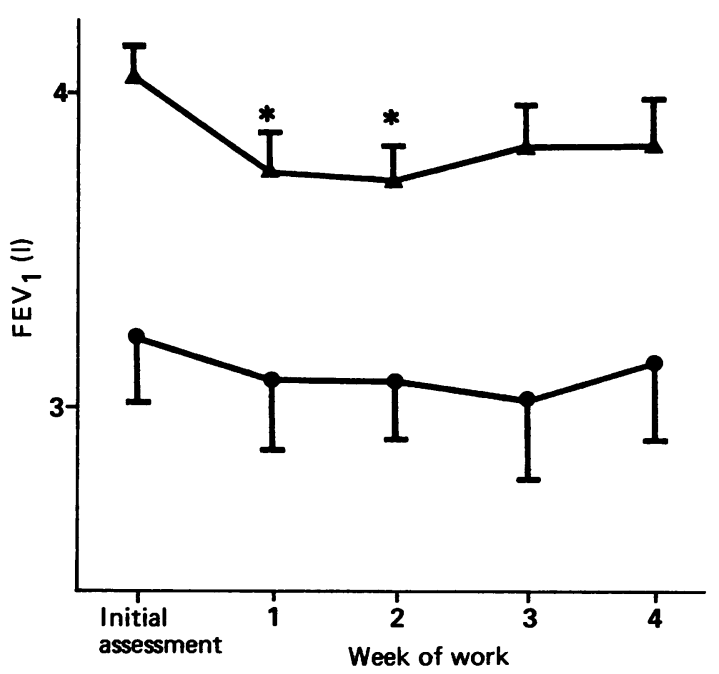

Figure 1 Forced expired volume in one second ( $\left.F E V_{1}\right)$ for grainhandlers (triangles) and non-exposed subjects (circles) at initial assessment and at end of each week of work.

Mean $\pm S E M{ }^{\star} p<0.05$ compared with initial assessment.

reduction in $\mathrm{FEV}_{1}$. In 24 subjects this reduction was more than $200 \mathrm{ml}$. The $\mathrm{FEV}_{1}$ of the grainhandlers decreased by a mean ( $95 \%$ confidence intervals) of $321 \mathrm{ml}(198-444)(\mathrm{p}<0.05)$ and $310 \mathrm{ml}(200-420)(p$ $<0.05$ ) after one and two weeks of work, respectively. There were no significant changes in the nonexposed subjects (fig 1). The mean changes in $\mathrm{FEV}_{1}$ were similar in the 23 grainhandlers who completed all five measurements of $\mathrm{FEV}_{1}$. In the grainhandlers the FVC decreased by a mean of $350 \mathrm{ml}(224-476)$ ( $p$ $<0.05)$ and $270 \mathrm{ml}(162-378)(\mathrm{p}<0.095)$ at one and

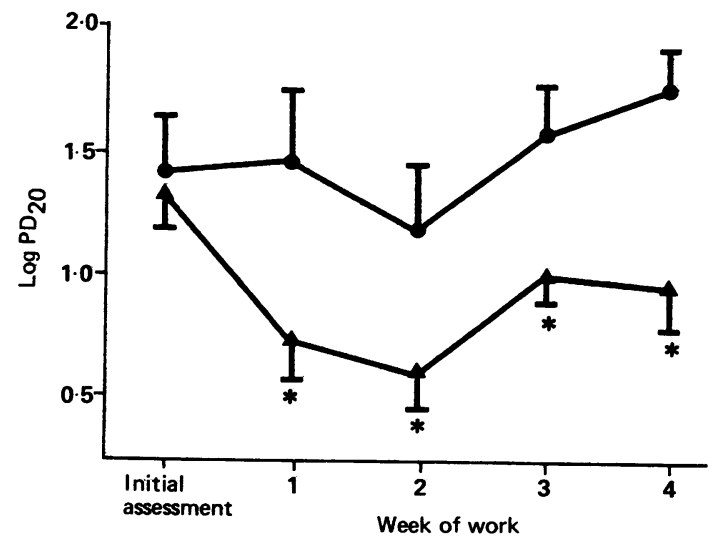

Figure 2 Bronchial responsiveness, expressed as log of dose of methacholine provoking a $20 \%$ fall in baseline $F E V_{1}$ (log $P D_{20}$ ) for grainhandlers (triangles) and non-exposed subjects (circles) at initial assessment and at end of each week of work. Mean $\pm S E M \star p<0.05$ compared with initial assessment. two weeks, respectively. The mean $\mathrm{FEV}_{1} / \mathrm{FVC}$ ratio remained relatively constant over the five assessments $(80 \%, 80 \%, 80 \%, 85 \%$, and $81 \%)$. Peak flow variability over the entire study period was $7 \cdot 3 \%$ $(2 \cdot 4-12 \cdot 2)$ in the grain handlers and $6 \cdot 2 \%(0 \cdot 7-11 \cdot 7)$ in the non-exposed subjects ( $p>0.05$ ). Peak flow variability was similar for both groups when calculated on a weekly basis. A PD $_{20}$ could be measured in $85^{\circ}{ }_{0}$ of the grainhandlers at the initial assessment. After starting work the percentage of subjects with a measurable $\mathrm{PD}_{20}$ were $98 \%, 98 \%, 93 \%$, and $86 \%$ after weeks $1,2,3$, and 4 respectively. $\mathrm{PD}_{20}$ decreased over the first week in 32 of the grainhandlers. The mean $\mathrm{PD}_{20}\left(95^{\circ}\right.$ o confidence interval) decreased in the grainhandlers from an initial value of $20.6 \mu \mathrm{mol}$
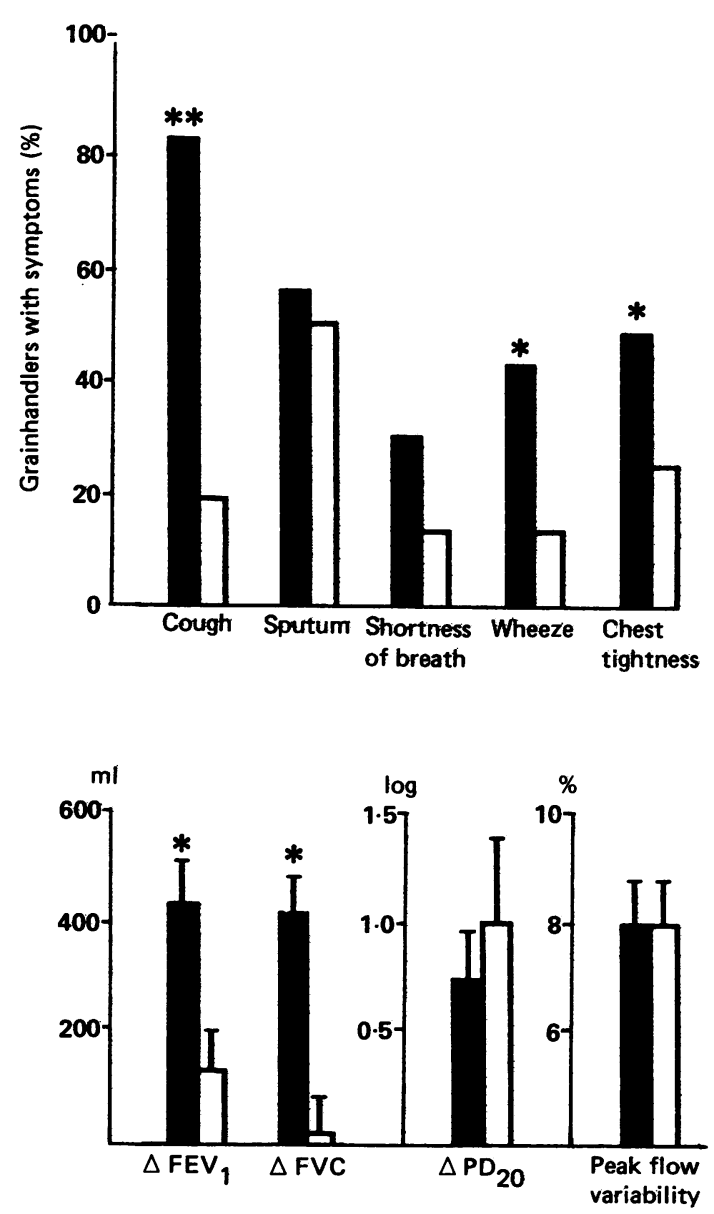

Figure 3 Effects of grain dust concentration on symptoms (top) and lung function (bottom). Percentage of grainhandlers reporting symptoms and changes in FEV $F V C$, peak flows, and log $P D_{20}$ (mean $\pm S E M$ ) in grainhandlers when working in jobs with total dust load $>20$ $\mathrm{mg} / \mathrm{m}^{3}$ (closed bars) are compared with those when working in jobs with total dust load $<10 \mathrm{mg} / \mathrm{m}^{3}$ (open bars). $\star_{p}<0.05 ;{ }^{\star \star} p<0.01$. 

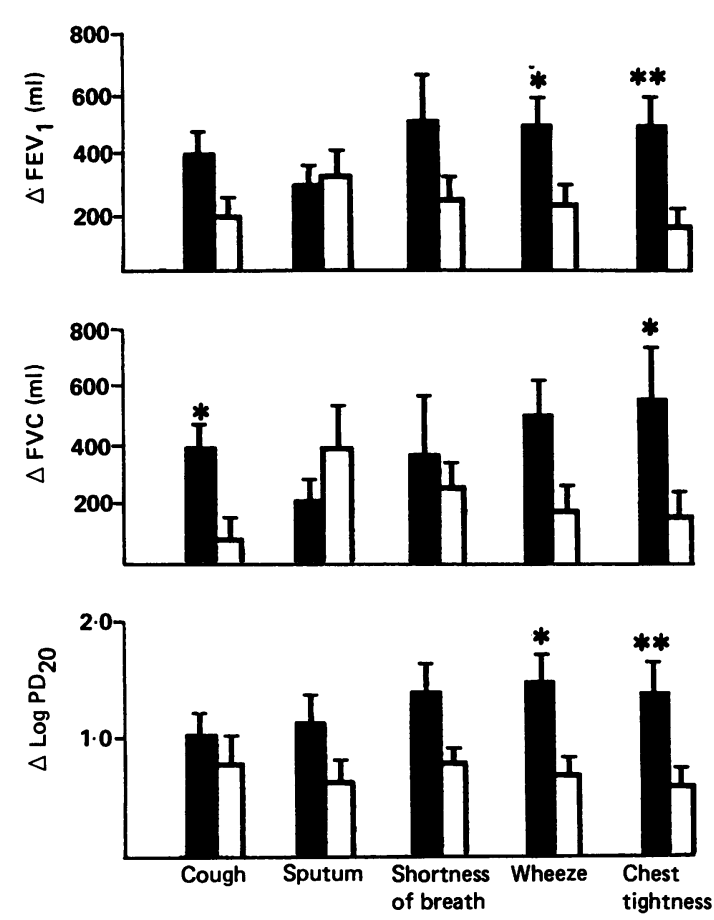

Figure 4 Changes in $F E V_{1}, F V C$, and $\log P D_{20}$ (mean $\pm S E M$ ) in grainhandlers reporting symptoms (closed bars) compared with those not reporting symptoms (open bars).

${ }^{\star} p<0.05 ;{ }^{\star \star} p<0.01$.

$(10 \cdot 3-41.2)$ to a mean of $6 \cdot 0 \mu \mathrm{mol}(2 \cdot 8-12 \cdot 5)$ after one week $(\mathrm{p}<0.05)$ and $4.3 \mu \mathrm{mol}(2 \cdot 1-8.8)$ after two weeks $(\mathrm{p}<0.05)$, and then remained below the preseason level until the conclusion of the study (fig 2). $F E V_{1}$ was weakly related to $P_{20}$ in the grainhandlers $(r=0.373)$ but not in the non-exposed subjects $(r=-0.022)$. The changes in $\mathrm{PD}_{20}$ were similar in the 22 grainhandlers assessed on all five occasions. The $\mathrm{PD}_{20}$ did not change significantly in the non-exposed subjects. Changes in lung function at work were not related to prestudy respiratory symptoms, prick skin tests or IgE uptake, or to initial lung function.

The frequency of positive skin test responses did not change between the beginning and end of the study. There were no differences in the grain dust specific IgE uptake between the grainhandlers and non-exposed subjects assessed as change over the course of the study or as the percentage of responders at the end of the study.

When the grainhandlers worked in jobs with high dust concentrations they reported more cough, wheeze, and chest tightness $(\mathrm{p}<0.01)$ than when they worked in jobs with low dust concentrations for the first two weeks of work (fig 3). There were no significant differences in the reporting of other symptoms. These relations were similar throughout the remainder of the period of work. Grainhandlers working in high dust jobs showed significantly $(\mathrm{p}<$ 0.025) greater decreases in $\mathrm{FEV}_{1}$ and $F V C$ relative to prestudy measurements than when they were working in low dust jobs (fig 3). Changes in bronchial responsiveness and peak flow variability, however, were not related to the measured dust concentrations.

Grainhandlers who reported chest tightness and wheeze in the first two weeks of the study had a greater fall in $\mathrm{FEV}_{1}(\mathrm{p}<0.05)$ and $\mathrm{PD}_{20}(\mathrm{p}<0.05)$ (fig 4) than those not reporting these symptoms. FVC decreased more in those grainhandlers who reported chest tightness and cough $(p<0.05)$. Daily peak flow variability was not related to the occurrence of upper or lower respiratory symptoms.

In this study neither atopy nor grain specific IgE uptake were related to frequency of symptoms or changes in $\mathrm{FEV}_{1}, \mathrm{FVC}$, and $\mathrm{PD}_{20}$.

\section{Discussion}

This study has shown that most of these seasonal grainhandlers developed respiratory symptoms and decreases in $\mathrm{FEV}_{1}, \mathrm{FVC}$, and $\mathrm{PD}_{20}$ within a week of starting work with grain. These changes were related to the level of grain dust exposure but not to markers of their allergic status. Two grainhandlers with a history of episodic wheeze, chest tightness or shortness of breath, and bronchial hyperresponsiveness $\left(\mathrm{PD}_{20}<\mu \mathrm{mol}\right)$ had pronounced reductions in $\mathrm{FEV}_{1}$ and FVC associated with symptoms of frank asthma and had left work. These results suggest that exposure to grain dust causes changes in lung function in most subjects and more severe reactions may occur in those with a history of asthma or increased bronchial responsiveness. This finding and interpretation is consistent with previous observations. ${ }^{34}$

Grainhandlers with little or no previous occupational exposure to grain dust were studied to reduce the selection bias that may occur among long term grainhandlers. ${ }^{2}$ The subjects in this study had a similar frequency of atopy and history of respiratory symptoms to those in a cross sectional population study in Western Australia. ${ }^{8}$ Although the nonexposed subjects used for comparison with the grainhandlers were not well matched for age and smoking history, examination of their questionnaire responses and their changes in lung function permitted the exclusion of factors other than exposure to grain dust causing changes in lung function.

The changes in FEV 1 and FVC observed in the grainhandlers was greatest in the first two weeks. In

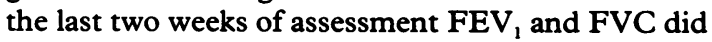
not differ from the initial values. The reasons for the recovery observed in this study are not clear. It was not due to grainhandlers with greater changes in lung 
function leaving work since the mean $\mathrm{FEV}_{1}$ was almost identical over the same period in those subjects who completed all five assessments. An overall decrease in grain dust concentrations could explain the recovery; however, the overlap in periods of employment, different times of starting employment, and the weekly job and shift rotation would have made any effect of general dust concentrations difficult to detect. Adaptive mechanisms within the grainhandlers may also have occurred. Adaptation to agents such as ozone have been attributed to altered neural mechanisms ${ }^{9}$; however, the role of such mechanisms and others such as mediator depletion have not been examined in grainhandlers.

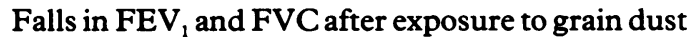
have been shown repeatedly in other studies. ${ }^{40-12}$ Changes in FEV, have been shown to occur after the first working day ${ }^{10}$ and may become more pronounced or persist at the end of the working week ${ }^{1013}$ or over longer periods. ${ }^{411}$ Lung function tends to return towards pre-exposure concentrations when subjects are removed from exposure. ${ }^{112}$ In this study measurements of $F E V_{1}$ and FVC and $\mathrm{PD}_{20}$ were made after only one week at work and did not indicate the changes that may have occurred from day to day. It was not possible to measure peak flows during a period before exposure and consequently a response that occurred during the first shift and persisted throughout the period of work may have been missed.

Bronchial responsiveness increased after one week at work in most grainhandlers and tended to return towards the pre-exposure level with continued exposure to grain dust. This pattern was identical in the grainhandlers who completed five assessments and therefore was not due to the more responsive grainhandlers leaving work. The level of bronchial responsiveness before working with grain has been associated with the development of symptoms. ${ }^{3}$ In this smaller sample of grainhandlers this finding was not confirmed. Nevertheless, the two grainhandlers who left work after one week had the lowest and third lowest $\mathrm{PD}_{20}$ of the subjects tested before the study and were among the five subjects with $\mathrm{PD}_{20}<4$ $\mu \mathrm{mol}$, the level associated with clinically evident asthma. ${ }^{7}$ Both these subjects had a history of variable wheeze, cough, and chest tightness before entering the study and the frequency of severe reaction in this study (two of 41 subjects) was similar to that reported previously. ${ }^{3}$

Serial changes in bronchial responsiveness in grainhandlers have been studied previously. Hensley et al observed increasing bronchial responsiveness over the course of a harvest season in a group of subjects with wheat associated "asthma."12 Bronchial responsiveness returned to the pre-exposure level after the harvest season. Since 28 of the 29 subjects were atopic, it was suggested that the increase in bronchial responsiveness may have been induced by allergic mechanisms. The current study indicates that many subjects will develop an increase in bronchial responsiveness when exposed to grain dust, which is independent of pre-exposure characteristics, including atopy.

The mechanisms underlying the increase in bronchial responsiveness observed in this study are unclear. Since both FEV 1 and $\mathrm{PD}_{20}$ fell at the same time there may simply be an effect of baseline airway calibre on measured responsiveness. This is partly supported by the correlation between these two variables $(r=0.373)$; however, there was considerable variability of $\mathrm{PD}_{20}$ at any given level of lung function. Increased bronchial responsiveness occurs after exposure to a range of substances including allergen $\mathrm{s}^{14}$ and ozone. ${ }^{9}$ The role of allergic factors in grain dust induced pulmonary disease remains unclear. ${ }^{15}$ The lower prevalence of atopy in long term grainhandlers may reflect selective forces related to the presence of asthma that are associated with atopy and increased airway responsiveness. ${ }^{41016}$ Non-allergic agents such as ozone can induce increased bronchial responsiveness, ${ }^{9}$ airway inflammation, ${ }^{17}$ and increased lung permeability. ${ }^{18}$ As a variety of non-specific airway irritants may produce similar changes, it has been suggested that the inflammation ${ }^{19}$ or altered lung permeability, ${ }^{20}$ or both, produced by such irritants may be the basis of the increased bronchial responsiveness.

A wide variety of materials is found in grain dust. Microscopy and culture of the grain at the worksite in this study isolated grass, grain, and fungal (common airborne and grain related) spores and particles. In addition grain dust contains many agents that can induce inflammation. ${ }^{21}$ Samples of grain dust from the worksite have also shown the presence of endotoxin, at a level high enough to cause symptoms (R Rylander, personal communication). The widespread non-specific changes observed in this study suggest that non-allergic processes may be the cause of these respiratory effects in most subjects.

We thank Dr B Walsh of the CSIRO Wheat Research Unit for the RAST responses to grain extracts, $\mathbf{M r}$ Geoff Taylor, chief scientific officer, Department of Occupational Health, for the measurement of dust concentrations, Dr Rose McAleer for the examination and culture of dust samples, and Elizabeth Bingle and Nellie Chew for typing the manuscript. We are grateful for the help of Cooperative Bulk Handling and the staff at the Northam grain terminal. The Asthma Foundation of Western Australia provided two vacation scholarships for this study. 
1 Cotton DJ, Dosman JA. Grain dust and health. I Host factors. Proceedings of international symposium on the effects of grain dust on human health. Ann Intern Med 1978;88:840-1.

2 Gerrard JW, Mink J, Sze-Shuen CC, Cheung C, Tan LK-T, Dosman JA. Nonsmoking grain handlers in Saskatchewan: airways reactivity and allergic status. J Occup Med 1979; 21:342-6.

3 Cookson WOCM, Ryan G, MacDonald S, Musk AW. Atopy, non-allergic bronchial reactivity, and past history as determinants of work related symptoms in seasonal grainhandlers. Br J Ind Med 1986;43:396-400.

4 James AL, Cookson WOCM, Buters G, et al. Symptoms and longitudinal changes in lung function in young seasonal grain handlers. Br J Ind Med 1986;43:587-91.

5 Medical Research Council. Committee on the aetiology of chronic bronchitis: standardised questionaries on respiratory symptoms. Br Med J 1960;ii:1665.

6 Morris JF, Johnson LC, Koski A. Spirometric standards for healthy nonsmoking adults. Am Rev Respir Dis 1971;103: 57-67.

7 Yan K, Salome C, Woolcock J. Rapid method for measurement of bronchial responsiveness. Thorax 1983;38:760-5.

8 Witt C, Stuckey MS, Woolcock AJ, Dawkins RL. Positive allergy prick tests associated with bronchial histamine responsiveness in an unselected population. J Allergy Clin Immunol 1986;77:698-702.

9 Dimeo MJ, Glenn MG, Holtzman MJ, Sheller JR, Nadel JA, Boushey HA. Threshold concentration of ozone causing an increase in bronchial reactivity in humans and adaptation with repeated exposures. Am Rev Respir Dis 1981;124:245-8.

10 doPico GA, Reddan W, Anderson S, Flaherty D, Smalley E. Acute effects of grain dust exposure during a work shift. Am Rev Respir Dis 1983;128:399-404.

11 Broder I, Mintz S, Hutcheon MA, Corey PN, Kuzyk J. Effect of layoff and rehire on respiratory variables of grain elevator workers. Am Rev Respir Dis 1980;122:601-8.

12 Hensley MJ, Scicchitano R, Saunders NA, et al. Seasonal variation in non-specific bronchial reactivity: a study of wheat workers with a history of wheat associated asthma. Thorax 1988;43:103-7.

13 Corey P, Hutcheon M, Broder I, Mintz S. Grain elevator workers show work-related pulmonary function changes and dose-effect relationships with dust exposure. $\mathrm{Br} J$ Ind Med 1982;39:330-7.

14 Cockcroft DW, Ruffin RE, Dolovich J, Hargreave FE. Allergeninduced increase in nonallergic bronchial reactivity. Clin Allergy 1977;7:503-13.

15 Chan-Yeung M, Wong R, MacLean L. Respiratory abnormalities among grain elevator workers. Chest 1979;75:461-7.

16 Broder I, Davies G, Hutcheon M, et al. Variables of pulmonary allergy and inflammation in grain elevator workers. $J$ Occup Med 1983;25:43-7.

17 Holtzman MJ, Fabbri LM, O'Byrne PM, et al. Importance of airway inflammation for hyperresponsiveness induced by ozone. Am Rev Respir Dis 1983;127:686-90.

$18 \mathrm{Kehrl}$ ER, Vincent LM, Kowalsky RJ, et al. Ozone exposure increases respiratory epithelial permeability in humans. $\mathbf{A m}$ Rev Respir Dis 1987;135:1124-8.

19 Chung KF. Role of inflammation in the hyperreactivity of the airways in asthma. Thorax 1986;41:657-62.

$20 \mathrm{Hogg}$ JC. Bronchial mucosal permeability and its relationship to airways hyperreactivity. J Allergy Clin Immunol 1981;67: 421-5.

21 Broder I, McAvoy D. Characterisation of precipitation reaction between grain dust and normal human serum and comparison of reactive and nonreactive grain handlers. Clin Immunol Immunopathol 1981;21:141-53.

Accepted 6 November 1989

\section{Vancouver style}

All manuscripts submitted to the $B r J$ Ind Med should conform to the uniform requirements for manuscripts submitted to biomedical journals (known as the Vancouver style)

The $B r J$ Ind Med, together with many other international biomedical journals, has agreed to accept articles prepared in accordance with the Vancouver style. The style (described in full in Br Med J, 24 February 1979, p 532) is intended to standardise requirements for authors.

References should be numbered consecutively in the order in which they are first mentioned in the text by Arabic numerals above the line on each occasion the reference is cited (Manson ${ }^{1}$ confirmed other reports ${ }^{2-5} \ldots$.). In future references to papers submitted to the $\mathrm{Br} J$ Ind Med should include: the names of all authors if there are six or less or, if there are more, the first three followed by et al; the title of journal articles or book chapters; the titles of journals abbreviated according to the style of Index Medicus; and the first and final page numbers of the article or chapter.

Examples of common forms of references are:

1 International Steering Committee of Medical Editors. Uniform requirements for manuscripts submitted to biomedical journals. Br Med J 1979; 1:532-5.

2 Soter NA, Wasserman SI, Austen KF. Cold urticaria: release into the circulation of histamine and eosino-phil chemotactic factor of anaphylaxis during cold challenge. $N$ Engl $J$ Med 1976;294:687-90.

3 Weinstein L, Swartz MN. Pathogenic properties of invading micro-organisms. In: Sodeman WA Jr, Sodeman WA, eds. Pathologic physiology: mechanisms of disease. Philadelphia: W B Saunders, 1974:457-72. 